\title{
Mitochondrial DNA-related cardiomyopathy and hearing loss
}

INSERM

\section{Source}

INSERM. (1999). Orphanet: an online rare disease and orphan drug data base. Mitochondrial DNA-related cardiomyopathy and hearing loss. ORPHA:1349

Maternally inherited cardiomyopathy and hearing loss is a mitochondrial disease described in two unrelated families to date that has a heterogeneous clinical presentation characterized by the association of progressive sensorineural hearing loss with hypertrophic cardiomyopathy and, in the majority of cases, encephalomyopathy symptoms such as ataxia, slurred speech, progressive external opthalmoparesis (PEO), muscle weakness, myalgia, and exercise intolerance. 